\title{
Learning from triads: training undergraduates in counselling skills
}

Kate Smith

This is the peer reviewed version of the following article:

Smith, K. 2015. Learning from triads: training undergraduates in counselling skills. Counselling and Psychotherapy Research,

which has been published in final form at doi: http://dx.doi.org/10.1002/ capr.12056

This article may be used for non-commercial purposes in accordance with the Wiley Terms and Conditions for Self-Archiving 


\section{Learning from triads: training undergraduates in counselling}

\section{2 skills}

3 Smith, K*.

4 Abertay University, Dundee, UK

$5 \quad$ *corresponding author Kate.smith@ abertay.ac.uk

6

7

Keywords: counselling; psychotherapy; skills; training; undergraduate

\section{Introduction}

12 Since the beginning of the Rogerian movement (Rogers, 1951), students training in

13 psychotherapy and counselling have been required to take part in 'live' demonstrations

14 of therapy. This practice is now common to all modalities of counselling skills training

15 (Hill, Stahl \& Roffman, 2007). Training in counselling and psychotherapy is provided

16 in both private organisations and voluntary agency contexts, as well as higher and

17 further education institutions, with a range of delivery formats e.g. part-time, full-time,

18 online, postgraduate, and undergraduate. Universities deliver around 50\% of training

19 (BACP, 2015). In the UK around 35 university programmes have integrated counselling

20 skills training in to undergraduate degrees (UCAS, 2014). For some students, entry on

21 to an undergraduate course may represent the first step towards professional training in

22 counselling or clinical psychology, while for others, it is simply training in transferable

23 skills. 
24 Generally courses providing undergraduate training in helping skills combining theory,

25 skills practice, and personal development aspects, have been shown to be effective, with even relatively short-term training shown to increase students' abilities to self-manage

27 and help others (Payne \& Woudenberg, 1978), and to develop conceptual and practice

28 skills, and self-awareness (Korn, 1980). In addition, the practical application of skills

29 during training has been found to significantly increase the use of skills during helping

30 events compared to training in which students simply observe or analyse skills

31 (Klevans, Voltz, \& Friedman, 1981). More contemporary research has focused on the pedagogy of training in counselling skills (Hill \& Lent, 2006), and the measurement of outcomes (Hill \& Kellems, 2002). One study, which examined the effectiveness of 34 undergraduates who had trained on a 'helping skills' course (Hill, Roffman, Stahl, 35 Friedman, Hummel \& Wallance, 2008), found good evidence for a range of skills being perceived as improved by clients and counselling students, as well as improvements indicated by objective measures of intervention such as the number of words used 38 during sessions.

In 2013 a report by the Higher Education Academy stated that there was a clear need for 40 an evidence base for best practice in teaching counselling and psychotherapy (Rutten \& 41 Hulme, 2013). To date, research into skills training has largely focused on effectiveness (Baker \& Daniels, 1989; Baker, Daniels \& Greeley, 1990; Buser, 2008); and the indirect psychological impact on the undergraduate student (e.g. Naar, 1974). Although the arguments for and against training within university contexts are discussed within the literature (e.g. Wheeler \& Miller, 2002), specific pedagogical activities in undergraduate settings have not been well researched.

47 A deeper understanding of counsellor training requires an examination of the ways in 48 which delivery and content impact upon learning. While it is generally accepted that 
instruction and modelling, practice and feedback, and space for reflection are all essential (Hill, et al, 2007), other variables such as class size, tutor input, and teaching and learning activities may be important, and student perspectives on training may provide guidance for educators for best practice.

This study focuses on one particular aspect of the training - skills training exercises and the impact of this practice on the overall learning experience of students. Skills training generally involves small groups of students turn-taking in applying particular counselling activities to each other, with reflective learning facilitated by feedback input from the perspective of the client, counsellor and observer(s) (Inskip, 1996; Swank \& McCarthy, 2013). Sharing of the experience of applying skills, observation of others, and experiencing the different counselling styles as a client, creates a situation where

60 the trainee can appreciate counselling from all perspectives (Hill, et al, 2007), making counselling personally relevant, increasing empathy towards clients (Anderson, Gundersen, Blanken, Halvorson, \& Schmutte, 1989) and broadening an understanding of counselling processes such as boundary maintenance and self-disclosure (Barnett, 2011; Hill \& Knox, 2001). Being in the role of the client, in particular, may involve disclosure of personal 'problem' material to peers, and so this pedagogical practice involves risk and relationship management for which students may be unprepared

67 (Latham, 1997). While institutional ethical considerations usually mean that use of personal material is not compulsory, Hill and colleagues (2008) found that during their study into the effectiveness of training, peer-counselling students voluntarily used personal difficulties rather than making up problems when in the role of clients.

71 This awareness of safety and risk and its role in the training environment (as opposed to

72 the counselling environment per se) has not been subject to a great deal of research (but 73 see Payne (2001) for a discussion of the role of safety in dance therapy for postgraduate 
trainees and Robson and Robson (2008) for experiences of students personal

75 development groups), and no studies look at how peer-counselling in counselling training might be best provided or developed within the undergraduate training cohort. Consideration should be given to responsibility of the training institution towards their students, as teaching and learning practices may involve voluntary engagement in selfdisclosure practices in a context where students may not be able to make an informed 80 choice, and disclosure is implicitly required by the context (Haney, 2004; Seawright \& Seawright, 2012). Counselling training is a potentially fertile ground for the divulgence of problematic stories and emotions and students may find themselves in a context where the role, and ratio, of trainers to students potentially precludes suitable monitoring of problems. In a qualitative study exploring the experiences of training for counselling undergraduates (Truell, 2001), two of the six students interviewed reported that the most stressful experience on the course was self-disclosure, with little perceived support from trainers due to blurred boundaries between students, and between students and tutors. Along with the stresses of disclosure, and perceptions of support roles, the suitability of students who have self-selected to study counselling, may be a concern as

90 the course may provide an arena for the presentation of unaddressed emotional needs and potentially challenging material (Guy, 1987). Self-disclosure may be implicitly or explicitly encouraged by tutors and peers, and be seen as evidence of emotional maturity or successful processing of events (Perillo, 1997). For students, potentially

94 high-risk subject matter such as mental illness, relationships and interpersonal issues, sexual abuse, physical health, substance use or misuse, and sexuality, may be current 96 (Storrie, Ahern \& Tuckett, 2010), and moral perspectives and socio-cultural beliefs may

97 also be challenged by peers. In a skills training context inappropriate disclosure or inappropriate response to disclosures either within or out-with the course context could 
99 lead to emotional distress, on-going interpersonal problems, a break-down or rupture in

100 the training group, loss of confidence and a negative impact on the learning experience.

101 This is of particular concern to an undergraduate cohort that is undertaking a three- or

102 four-year period of study and who may share time both within the programme and

103 socially.

104

105 This research study explores the experiences of undergraduate students training in 106 counselling skills as part of their Psychology and Counselling undergraduate degree.

107 The aim of the research is to examine the perspective of students engaged in triads, and

108 ask what challenges may arise for this group in terms of self-disclosures, with the

109 objective of informing on teaching in further and higher education.

110

111 Method

112 Semi-structured interviews were carried out on a cohort of students focusing

113 specifically on the experience and impact of self-disclosure during training. The

114 interviews and analysis were carried out by the lead counselling tutor on the

115 undergraduate programme. The initial research question was based on a professional

116 observation of the different dynamics between a group of undergraduate students

117 compared to a group of mature postgraduates on a comparable course. The

118 undergraduate students were less engaged with disclosure, reporting it as difficult, and

119 how it could impact on their relationships with their cohort outside the classroom.

\section{Participants}

122 Twelve participants (identified as A-L) were recruited from a cohort of 20

123 undergraduates approaching the end of their second year of a BSc Psychology and 
124 Counselling. Their counselling-specific training had comprised one introductory

125 module, and at the time of interview, between two and three counselling skills modules

126 (approximately 25\% of their full-time timetable). Ages ranged from 19-26 (mean

127 20.58, sd 1.98), and included two males and 10 females.

128 The training provided in the counselling skills modules was embedded within a three-

129 hour long, weekly session. The sessions themselves involved a taught component,

130 followed by a description or demonstration of an intervention or skill e.g. person-

131 centred counselling, followed by the use of empathic reflection in practice. Students

132 were then split in to 'triad' working groups of three/four, and practised the skill on one

133 another with the roles of client, counsellor and observer(s). Following the skills

134 practical, student personal development groups provided the opportunity to reflect on

135 the theory and skills with semi-structured tasks. It is important to note that while the

136 use of personal material was not compulsory, it was encouraged when in the role of a

137 client in the triads.

138

139 Data collection and analysis

140 Semi-structured interviews, each lasting approximately 45 minutes, were conducted by

141 the researcher following guidelines laid out by Whiting (2008). The development of

142 interview questions was guided by Agee (2007) and focused on preparedness and

143 preparation for triads, on-going training experiences and disclosures, changes and

144 learning over time, and reflections on the process.

145 Interviews were audio recorded and transcribed as soon as possible following the

146 interview. Thematic analysis followed a process of open-coding for initial meaning

147 units within the text followed by categorisation of themes. Returning to the text to

148 verify the categories allowed for the adjustment and removal of repeated or over- 
149 lapping conceptual units. Then a stage involving axial coding (linking categories), and 150 higher order or 'selective' coding was undertaken to establish a conceptual framework 151 to best exemplify the data (Braun \& Clarke, 2006).

\section{Ethical considerations}

154 British Association for Counselling and Psychotherapy (BACP) ethical guidelines for 155 counsellors underpinned the research process (Bond, 2004), which was given approval 156 by the university's Ethics Committee. Participation in the study was voluntary, and

157 informed, written consent was obtained.

158 Specific ethical considerations related to the relationship between the researcher, a

159 member of university staff, and the students. The potential impact of this relationship

160 was two-fold. First, it would influence the students' perception of their obligations to 161 take part, and to report particular aspects of their experience in favour of others. Second,

162 the tutor would be influenced by what was said and the study would become a platform

163 for specific feedback (which should occur through formal programme-level channels

164 and meetings arranged by the institution). In order to mitigate this blurring of

165 boundaries between the course and the study, student recruitment occurred outside of 166 class through emails sent to potential participants, and statements were made to clarify

167 the purpose of the study and provide assurance of neutrality and confidentiality.

168 Participants were also encouraged to bring issues of complaint to the termly programme

169 meetings, as what was divulged during the study was not fed directly into teaching.

171 Reflections from the author:

172 As the lead tutor and co-ordinator of these students' triads, I approached the project as a 173 way of addressing my personal concerns about a teaching practice that appeared to be 
commonplace. I wanted to ask questions of the students, not as a tutor in conversation,

175 but in a way that allowed more exploratory and honest accounts. Although triads were 176 the activity on this course with which I had least involvement (the main facilitation of

177 skills practices being carried out by other tutors), I had the job of 'designing' the 178 practical work, and also of facilitating post-triad reflective discussion. Questions in my 179 head during the research revolved around bias in the reports, and bias in the analysis:

180 'Are these students telling me what I want to know, or messages they want me to hear?'

181 'What am I not seeing, am I blindsided by expectation?' Participants were assured that

182 all comments would be treated with equal value both in the study information and 183 verbally prior to- and during the interviews. It was also verbally clarified that 184 participation (or not) would have no impact on their studies: for example, opinions and 185 experiences of triads were not made available to, or discussed with, the triad tutors. I 186 also approached the interviews from the perspective of acceptance and respect for what 187 was being presented, to minimise, as far as possible, interpretation from my perspective: 188 to honour participants' contributions at 'face value'. The systematic analysis of the 189 transcripts involved an extra layer of complexity for me, as there were aspects of the 190 accounts that were expected, but also aspects that were surprising. I was also aware of my professional position, and the risk of finding evidence of poor or unethical practice. I was prepared to follow ethical guidelines but was also aware that in the long-term I may have to accept that the teaching of the course might have to change. On the other

194 hand my involvement with the students allowed me to share their context and 195 knowledge, which, , I believe, enhanced my understanding of the students' perspectives and experiences. 
200 Results:

201 Three theme clusters emerged from the data (table 1), the first relating to the functioning 202 of the cohort including relationships inside and outside the class, premature intimacy of 203 the cohort, and overall group dynamics. A second cluster existed around the personal 204 impact of disclosures, which included the impact of saying too much, the consequences 205 of breaches of trust, and a third concerning the impact on learning. The quotes reported 206 are identified by participant letter (A-L), and the transcript line number.

208 (insert table 1 about here)

\section{Functioning of the cohort:}

210 This theme was indicated by an awareness in the participants that there were both

211 shared and individual rules on how to manage what was divulged during the triads:

A275: 'It's just clear that you wouldn't take that outside (the group), like maybe you could look at someone and say “alright?” but I wouldn't think of bringing it up.'

H121: 'Some of us just got it, like in that early discussion group, it all clicked and we were like permission to share, it kind of made it easy that the rules were talked about.' E332: 'I still monitor what I can say, like I have to prepare for triads to get a problem that's the right size, sometimes I don't want to talk and that's okay, it's not a problem.' 
223 Reports indicate that the group functioned on very personal level from early on. This

224 was felt to be an unusual experience for students, and unlike that of other groups. A strong sense of positive group identity pervaded many of the reports. unusual because we have like grown up really fast together.'

An awareness of the impact of intimacy, which came out of disclosure, was viewed positively and negatively by participants. to the class, I've told them stuff I wouldn't say to my mum.'

This related to discussions around the ideas of sharing with friends and sharing with peers on the course, with some students distinguishing between them. from one week to the next except in class but they are easier to work with, you

238 Some of the students reported negative feelings around the formation of sub-groups

239 within the teaching cohort, impacting on the way triads worked. know?' tend to just not do our work.'

\section{Personal impact}


244 This theme cluster concerns the ways in which being on the course has impacted on the

245 students personally, in particular the impact of what is said, when too much might be 246 shared, and the consequences of breaches of trust.

248 Students sometimes felt that they were managing a tension between their social 249 presentations of themselves and the ways that they were expected to be open and honest 250 on the counselling course.

251 underneath.'

This was highlighted by important aspects of the emotional experience and how these were managed by others on the course.

C167: 'My eyes were red from crying, and everyone knew why, but it was fine, I mean they knew but no-one made a fuss when I saw them later.'

260 The students were very aware of the real or potential impact of sharing too much with

261 peers. Sometimes sharing left the students with sense of reduced safety. to think that they were down the pub telling everyone, "Oh yeh there's this girl on my course with an alki for a mum.",

266 There was awareness of the need to limit what is said in triads. 
I56: 'God, I have to be careful because if I am on a rant it all comes out, I don't hold back and I had to learnt to just think of how it would sound, and what I can talk about in like 15 minutes....sometimes the sessions would just be one person going on, and that means you get in to a lot of $\mathrm{s}^{* * *}$.'

271 There was also a need to ensure that the listener was not overloaded, or too concerned.

272
D320: 'To be honest I don't think he'd cope with it all, I didn't want to tell him all about it and then he'd not know what to say and that would be just awkward.'

E178: 'There's a limit, not just time, but like a limit on how much you put on people, they are going to be thinking about it all day.'

Sometimes what was shared in the triads left a mark, and this impact left long-term feelings of discomfort and concern:

K365: 'I just felt for her, really, really bad, like so sorry that this had happened, and I didn't know what to say, and when I saw her later I wanted to say "are you okay?" but wasn't allowed and so I've never even said anything to her.'

Putting trust in others, and being placed in a situation where trust is required, presented problems especially at the start of the training. Several participants mused about when and where breaches were being risked, that someone might take the information out of the group, but also that under some circumstances breaches should occur for the benefit of other students.

G214: 'My feeling was that you couldn't talk about it outside, like you would never talk about it outside but this time we all left together and were in the hall before I thought ooh no shut up.' 

that there is an issue?'

291

294

This perceived risk was matched in many reports by a sense of trust:

C12: 'We've all been like so trusting over the last year or so that no-one would break that now, it's like a pact between us.'

The role of the tutors was again important in terms of emotional support, and for formal and informal advice. They were seen as a resource.

E54:' So I spoke to $\mathrm{X}$ (tutor) about it, and she was great, she suggested that I went to student services, which I did and I've been going there for four weeks now.'

\section{Impact on learning}

This theme reflects the various ways that the triads impacted on learning in the group. The triads were approached with various levels of trepidation, but recognised as an important aspect of training.

G62: 'I can still remember oh my gosh when X (tutor) said we were going to be counselling each other, I was so nervous.'

H300: 'You have to be careful with feedback, you want them to be honest but you don't want to say anything negative to them.'

E51: 'You can’t learn without it.'

Some of the students reported going through a stage of withdrawing from the group, not wanting to take part in the triads or reverting to role-play as a client. 

B201: 'There was definitely a stage where I went right back and thought, these aren't people who need to talk to me right now, I don't want to engage you

313 For some, the major challenge was to understand the need for skills practice, and why

314 taking the role of the client is so important to personal development. from this, and I still can't put my finger on it.'

317 Ultimately many of the students summarised their experiences as being hard going but

318 worth it, with the positive aspects and learning far outweighing the negative.

A197: '..at that point I really got it, it clicked and I thought I had really learnt something significant, not just about counselling, but about me and them, it changed me.'

\section{Discussion}

324 The key themes for the participants in this study were around aspects of managing

325 personal and group processes and boundaries while engaging in counselling skills

326 training, with clear links being drawn between the experiences in triads and those of 327 self-awareness and relationships within and outside the cohort. As was found by Truell 328 (2001) and Latham (1997), aspects of the risks of structured intimacy and the use of 329 personal material in triads were clearly impactful, but results also indicate participants' 330 awareness of the complexities of confidentiality and the impact of trust on relationships.

331 The participants appear to have taken the first steps towards building a therapeutic community, developing interpersonal awareness, and boundaried and trustful 
333 relationships with one another in a way similar to that reported by Payne and

334 Woudenberg (1978), and Korn (1980). Overall the interviewees revealed themselves to

335 be highly self-aware, and aware of the emotions of their peers.

336 One further important aspect, which was highlighted in the Truell (2001) study, is the

337 sense of the tutors being a continued and stable presence in the group. Teachers of

338 counselling should be aware of this role when running courses of this type.

339 The key issue of the personal impact of training, both in the short and long-term, is an

340 established part of postgraduate training and has been well explored, e.g. Folkes-

341 Skinner, et al, (2010). However, this is less so for undergraduates, and this study reveals

342 the tensions within and between students, who manage their learning activities by

343 deliberate personal choice-making in terms of disclosure and sharing. This leads to a

344 sense, at times, of voluntary disengagement.

345 Researchers approaching evaluations of teaching practices have tended to examine

346 outcomes of training, and although this was asked about in interviews, the participants

347 in this study talked less about effectiveness, but more on the experience and challenges

348 of the practice. Triad work on this course functioned as a way of developing

349 counselling intervention skills, but also as a catalyst for personal reflection and

350 development, and it was the impact of this secondary role, which appears to be

351 paramount in the reports. Although it brings inherent stresses and challenges, self-

352 disclosure in triad training was a personal choice for the students, and appears to be an

353 appropriate learning activity for this undergraduate group.

354 The implications of these results are that teachers and teaching providers need to be 355 aware of the demands placed on undergraduates undertaking training of this type, and 356 should monitor students closely, and also make efforts to clearly describe these 357 demands to students thinking of entering the programme. For students during training, 
358 it may be that the individual interactions and group dynamics become the focus of the

359 learning rather than the skills themselves, and adaptations to teaching and learning - for

360 example by allowing discussions within the group, and individually with tutors - could

361 support this process and mitigate potential problems. There is also variability between

362 students in the ability and willingness to engage in skills practices, which has

363 implications for institutions offering and assessing a teaching and learning activity that

364 not all students are able to fully engage, and so programme providers should consider

365 the impact of this during evaluation of learning.

366

367

368 Limitations:

369 Limitations include the use of participants from a single undergraduate course from a

370 UK institution which means that the experiences reported were to some extent shared.

371 The cohort was also relatively young for students of counselling, and this further

372 reduces the generalisability of the findings to other groups. The implications of the

373 relationship between the researcher and participants is discussed in the methods section,

374 and include the assumption of 'face-value' in the reports of participants, and also

375 possible bias on the part of the investigator..

376 An objective measure of effectiveness of the counselling training in improving skills

377 was not the focus of this project and participants did not evaluate the training, as

378 opposed to the experience of training. More exploration of participant perception of

379 skills learning would constitute a valid focus for a follow-up study. In addition to

380 finding no evidence for overall effectiveness of practical skills training, this study failed

381 to provide evidence for learning being enhanced by reflective engagement, and future 
382 research should focus on widening understanding of the impact of pedagogical 383 approaches on academic performance.

384

385 Conclusion

386 While reflective experiential learning is potentially important as both the means and the

387 ends of counselling skills training, there are potential pitfalls, and little published

388 guidance on how this should be managed for undergraduate courses. In this paper the

389 experiences of students who self-disclosed during practice triads were reported, and

390 highlights the personal and academic impact of this kind of learning activity.

391

392 
393 Agee, J. (2009). Developing qualitative research questions: A reflective process. International Journal of Qualitative Studies in Education, 22(4), 431-447.

395

396

Anderson, D. D., Gundersen, C. B., Banken, D. M., Halvorson, J. V., \& Schmutte, D. (1989). Undergraduate role players as clients for graduate counseling students. Teaching of Psychology, 16(3), 141-142.

BACP British Association for Counselling and Psychotherapy. (2015). BACP consultation: Practitioner education and development. Lutterworth, BACP.

Baker, S. B., \& Daniels, T. G. (1989). Integrating research on the microcounseling program - a meta-analysis. Journal of Counseling Psychology, 36(2), 213-222.

Baker, S. B., Daniels, T. G., \& Greeley, A. T. (1990). Systematic training of graduatelevel counselors - narrative and meta-analytic reviews of 3 major programs. Counseling Psychologist, 18(3), 355-421.

Barnett, J. E. (2011). Psychotherapist self-disclosure: Ethical and clinical considerations. Psychotherapy, 48(4), 315-321.

Bond, T. (2004). Ethical guidelines for researching counselling and psychotherapy. Lutterworth, BACP.

Braun, V., \& Clarke, V. (2006). Using thematic analysis in psychology. Qualitative Research in Psychology, 3(2), 77-101.

Buser, T. J. (2008). Counselor training: Empirical findings and current approaches. Counselor Education and Supervision, 48(2), 86. 
413 Folkes-Skinner, J., Elliott, R., \& Wheeler, S. (2010). 'A baptism of fire': A qualitative

414 investigation of a trainee counsellor's experience at the start of

$415 \quad$ training. Counselling and Psychotherapy Research, 10(2), 83-92.

416 Guy, J. (1987). The private life of the psychotherapist. London: Wiley.

417 Haney, M. R. (2004). Ethical dilemmas associated with self-disclosure in student $418 \quad$ writing. Teaching of Psychology, 31(3), 167-170.

419 Hill, C., \& Knox, S. (2001). Self-disclosure. Psychotherapy, 38(4), 413-417.

420 Hill, C. E., \& Kellems, I. S. (2002). Development and use of the helping skills measure to assess client perceptions of the effects of training and of helping skills in sessions. Journal of Counseling Psychology, 49(2), 264-272.

423

424

425

426

427

428

430

Hill, C. E., \& Lent, R. W. (2006). A narrative and meta-analytic review of helping skills training: Time to revive a dormant area of inquiry. Psychotherapy (Chicago, Ill.), 43(2), 154-172.

Hill, C. E., Roffman, M., Stahl, J., Friedman, S., Hummel, A., \& Wallace, C. (2008). Helping skills training for undergraduates: Outcomes and prediction of outcomes. Journal of Counseling Psychology, 55(3), 359-370.

Hill, C. E., Stahl, J., \& Roffman, M. (2007). Training novice psychotherapists: Helping skills and beyond. Psychotherapy (Chicago, Ill.), 44(4), 364-370.

431 Inskip, F. (1996). Skills training for counselling. London: Cassell.

432 Klevans, D. R., Volz, H. B., \& Friedman, R. M. (1981). A comparison of experiential and observational approaches for enhancing the interpersonal communication skills 
of speech-language pathology students. Journal of Speech and Hearing Disorders, 46, 208-213.

436

437

Korn, P. R. (1980). An undergraduate helping skills course: Skill development and career education. Teaching of Psychology, 7(3), 153-156.

Latham, W. (1997). Peer counseling: Proceed with caution. Educational Leadership, 55(2), 77-78

Naar, R. (1974). Personality changes and innovations in teaching counseling skills to undergraduates. Psychotherapy: Theory, Research \& Practice, 11(1), 52-57.

Payne, H. (2001). Student experiences in a personal development group: The question of safety. European Journal of Psychotherapy \& Counselling, 4(2), 267-292.

Payne, P. A., \& Woudenberg, R. A. (1978). Helping others and helping yourself: An evaluation of two training modules in a college course. Teaching of Psychology, 5(3), 131-134.

Perillo, L. (1997, November 28th). When the classroom becomes a confessional. The Chronicles of Higher Education.

Robson, M., \& Robson, J. (2008). Explorations of participants' experiences of a personal development group held as part of a counselling psychology training group: Is it safe in here? Counselling Psychology Quarterly, 21(4), 371-382.

Rogers, C. R. (1951). Client-centred therapy. London: Constable.

Rutten, A., \& Hulme, J. (2013). Learning and teaching in counselling and psychotherapy. York: The Higher Education Academy. 
Seawright, H. R., \& Seawright, B. K. (2012). College students self-disclosure in writing assignments: Professional and ethical issues. International Journal of Modern Education Forum, 1(1)

Storrie, K., Ahern, K., \& Tuckett, A. (2010). A systematic review: Students with mental health problems - a growing problem. International Journal of Nursing Practice, $16,1-6$.

Swank, J. M., \& McCarthy, S. N. (2013). The counselor feedback training model: Teaching counseling students feedback skills. Adultspan Journal, 12(2), 100-112.

Truell, R. (2001). The stresses of learning counselling: Six recent graduates comment on their personal experience of learning counselling and what can be done to reduce associated harm. Counselling Psychology Quarterly, 14(1), 67-89.

UCAS. Retrieved from http://www.ucas.com/ (retrieved 03/01/14)

Wheeler, S., \& Miller, H. (2002). Counselling and psychotherapy: Should it be taught in universities? review of three papers. European Journal of Psychotherapy \& Counselling, 5(4), 407-414.

Whiting, L. S. (2008). Semi-structured interviews: Guidance for novice researchers. Nursing Standard (Royal College of Nursing, 22(23).

Author Biography:

Kate Smith is a lecturer in counselling at Abertay University, Dundee. She is a registered counsellor with the British Association for Counselling and Psychotherapy. Her doctoral studies were on the impact of narrative on autobiographical memory for people with depression, and her other research 
477 interests include the social and emotional effects of a diabetes, and ethical 478 training issues in mental health. 
Table 1: Emergent themes and theme clusters

\begin{tabular}{|c|c|c|}
\hline Theme cluster & Theme & Participant \\
\hline Functioning of the cohort & $\begin{array}{l}\text { Group rules } \\
\text { Depth of group engagement } \\
\text { Not just friendship } \\
\text { Process of group development } \\
\text { Challenges of learning activity } \\
\text { Problems within the group } \\
\text { Formation of sub-groups }\end{array}$ & $\begin{array}{l}\text { A, B, C, D,E,F, G, H, J, K, L } \\
B, D, J, K, L \\
\text { A, C, D, E, G, H, K } \\
\text { A, B, E, H, J } \\
D, E, F, H, I, L \\
\text { A, B, C, E, F, H, J, K, L } \\
\text { C, E, G, F, H, L }\end{array}$ \\
\hline Personal impact & $\begin{array}{l}\text { Social versus group presentation of self } \\
\text { Emotional impact } \\
\text { Self-policing } \\
\text { Policing for others } \\
\text { Emotional hang-over from triads } \\
\text { Trust } \\
\text { Need for tutor support }\end{array}$ & $\begin{array}{l}\text { A, B, D, H, J, L } \\
\text { C, F, G, H, J } \\
\text { A, C, D, G, H, L } \\
\text { A, B, C, D, G, L } \\
\text { C, D, G, J, K } \\
\text { B, C, E, F, G, I, J, K, L } \\
\text { A, B, C, D, E, F, G, H, J, K, L }\end{array}$ \\
\hline Impact on learning & $\begin{array}{l}\text { Being prepared for triads } \\
\text { Not wanting to take part } \\
\text { Role of triads in learning } \\
\text { Outcomes of the course }\end{array}$ & $\begin{array}{l}\text { A, B, C, D, E, F, G, H, I, J, K, L } \\
B, E, F, K \\
\text { A, C, I, J, L } \\
\text { A, B, D, E, F, G, H, I, K, L }\end{array}$ \\
\hline
\end{tabular}

